\title{
Perbedaan Intensitas Nyeri Haid Sebelum dan Sesudah Diberikan Kompres Hangat pada Remaja Putri di Universitas Dharmas Indonesia
}

\author{
Husna $^{1}$ \\ ${ }^{1}$ Dosen Program Studi D3 Kebidanan Universitas Dharmas Indonesia \\ Corresponding author: Husna (husnaskmmkm1451@yahoo.com)
}

Received 22 September 2018; Accepted 22 September 2018; Published 24 September 2018

\begin{abstract}
Adolesence or adolescence comes from the Latin adolescere (the difference is adolecentia, which means teenager) which means "body" or grow into adulthood. In englishmurabaqoh is adolecence which means at-tadaruj (gradual). So the meaning is gradually towards physical, resourceful, psychological, and social and emotional maturity. Dysmenorrhoea is pain during menstruation, usually with cramping and is concentrated in the lower abdomen. Complaints of menstrual pain can occur ranging from mild to severe. The severity of dysminorrhoea is directly related to the length and amount of menstrual bleeding. As is known menstruation almost always followed by a feeling of heartburn / pain. Pain intensity is a description of how severe pain is felt by individuals, measurement of pain intensity is very subjective and individual and the possibility of pain in the same intensity is felt very different by two different people, therefore Descriptive and numerical pain scales were used. This study aimed to determine whether there was a difference in the intensity of menstrual pain before and after warm compresses on young women at the Indonesian Dharmas University. This study uses an experimental method with the design of one group pretest-post test only design. The location of the study was conducted at the Indonesian Dharmas University. When the research was conducted on August 19-24. The research sample is the total population. Data analysis used is univariate and bivariate analysis. Based on the results of the study using Wilcoxon found that there is a p-value of $0.005<0.05$, meaning that there is a difference in the intensity of menstrual pain before and after giving a warm compress.
\end{abstract}

Keywords: Teenagers, dysminorrhea, pain intensity

Copyright @ 2018 STIKes Surya Mitra Husada

All rights reserved.

This is an open-acces article distributed under the terms of the Creative Commons Attribution-ShareAlike 4.0 International License. 


\section{PENDAHULUAN}

Masa remaja adalah masa peralihan dari anak anak ke dewasa. Defenisi remaja sendiri dapat ditinjau dari tiga sudut pandang yaitu secara kronologis, remaja adalah individu yang berusia antara 11-12 tahun sampai 20-21 tahun. Secara fisik, remaja ditandai dengan adanya perubahan ukuran dan penampilan fisik dan adanya kemampuan bereproduksi, dan seacara psikologis, remaja mengalami perubahan pada kognitif, mental, sosial, dan moral (kusmiran, 2012). Periode masa remaja ini sering disebut masa pubertas yaitu bagian dari proses perkembangan dengan adanya kematangan organ seksual dan kemampuan bereproduksi, yang ditandai dengan terjadinya menstruasi pertama (menarche) (Widyastuti, 2009).

Remaja atau adolesence berasal dari bahasa latin adolescere (kata bedanya, adolecentia yang berarti remaja) yang berarti " tubuh" atau tumbuh menjadi dewasa. Dalam bahasa inggris murabaqoh adalah adolecence yang berarti at-tadaruj (berangsur-angsur). Jadi artinya adalah berangsur-angsur menuju kematangan secara fisik, akal, kejiwaan, dan sosial serta emosional (Pudiastuti, 2012).

Dismenorea (Nyeri haid) merupakan salah satu keluhan yang sering dialami wanita muda. Dismenorhea merupakan menstruasi yang disertai rasa sakit yang hebat dan kram, kekakuan atau kekejangan dibawah perut yang terjadi pada waktu menjelang atau selama menstruasi, yang memaksa wanita untuk beristirahat atau berakibat pada menurunnya kinerja atau kurangnya aktifitas sehari hari (Nafiroh \& Indrawati, 2013).

Dismenorea adalah nyeri saat haid,biasanya dengan rasa kram dan terpusat di abdomen bawah. Keluhan nyeri haid dapat terjadi bervariasi mulai dari yang ringan sampai yang berat. Keparahan disminorea berhubungan langsung dengan lama dan jumlah drah haid. Seperti diketahui haid hampir selallu diikuti dengan rasa mulas/nyeri (Prawirohardjo, 2011).

Pada umumnya wanita merasakan keluhan berupa nyeri atau kram perut menjelang haid yang dapat berlangsung hingga 2-3 hari, dimulai sehari sebelum mulai haid. Nyeri perut saat haid (dismenorea) yang dirasakan setiap wanita berbeda-beda, ada yang sedikit terganggu namun ada pula yang sangat terganggu hingga tidak dapat menjalankan aktivitas sehari-hari dan membuatnya harus istirahat bahkan terpaksa absen dari perkuliahan/pekerjaan. Dismenorea didefinisikan sebagai nyeri uterus yang bersifat siklik yang terjadi sebelum atau selama menstruasi (Andriyani, 2013).

Menurut World Health Organization (WHO) didapatkan angka kejadian disminorea sebesar 1.769.425 jiwa (90\%) wanita. Angka kejadian diminorea di indonesia sebesar 107.673 jiwa $(64,25 \%)$ wanita, yang terdiri dari 59.671 jiwa $(54,89 \%)$ mengalami disminorea primer dan 9.496 jiwa $(9,36 \%)$ mengalami disminorea sekunder (Zshasa et al,2016).

Di Sumatera Barat belum ada data yang pasti mengenai disminorea pada tahun 2016 jumlah estimasi penduduk di Sumatera Barat wanita berjumlah 2.642.255 jiwa, sedangkan jumlah usia muda $>15$ tahun berjumlah 774.753 jiwa. Estimasi jumlah anak usia 7-12 tahun di Sumatera Barat adalah 303.554 jiwa. Presentase puskesmas menyelenggarakan kegiatan kesehatan remaja di Sumatera Barat berjumlah 42,42\% dari jumlah puskesmas. Dikabupaten Dharmasraya jumlah anak usia 7 - 12 tahun berjumlah 27.241 jiwa (Kementrian Kesehatan RI, 2017).

Penyebab disminorea primer belum diketahui secara jelas, pada wanita yang mengalami disminorea tetap normal. Adanya penumpukan bahan kimia dalam tubuh yang disebut prostaglandin dilapisan rahim dalam jumlah normal,prostaglandin berfungsi membantu rahim berkontraksi dan mengeluarkan dan mengeluarkan lapisan rahim selama periode. Pada wanita yang mengalami nyeri haid batau disminorea tampaknya ada penumpukan prostaglandin dalam jumlah terlalu banyak. Hal ini akan mengurangi suplai darah kerahim dan menyebabkan rasa sakit. Sedangkan penyebab disminorea sekunder umumnya terjadi pada wanita yang lebih tua adanya gangguan yang terjadi pada uterus seperti adanya endometreosis, fibroid,atau infeksi rahim.

Dampak Disminorea dampak yang terjadi jika disminorea ( nyeri haid ) tidak ditangani adalah gangguan aktifitas hidup sehari-hari,Retrogret( menstruasi yang bergerak mundur,infertilitas (kemandulan),Kehamilan atau kehamilan tidak terdeteksi ektopik pecah,kista pecah,perforasi rahim dari IUD dan infeksi. Selain dari dampak di atas,konflik emosional,ketegangan dan kegelisahan semua itu dapat memeainkan peranan serta menimbulkan perasaan yang tidak nyaman dan asing. Ketegangan biasanya menambah parahnya keadaan yang buruk setiap saat, Sedikit tidak merasa nyaman dengan cepat berkembang menjadi suatu masalah besar dengan segala kekesalan yang menyertainya. Dengan demikian kegelisahan,perasaan tidak gembira atau juga perasan tertekan semua 
itu bukanlah hal yang tidak biasa. Oleh karena itu pada usia remaja nyeri haid (disminorea) harus ditangani agar tidak terjadi dampak seperti hal-hal yang di atas (Devi Eka Widiyanti,2013).

Solusi disminorea, pada saat haid ini tidak ada pencegahannya. Cara mengatasi nya disminorea yang paling sederhana adalah mencoba mengalihkan rasa nyeri pada kegiatan lain,seperti mandi air hangat,atau meletakkan sesuatu yang hangat di bagian perut seperti (kompres hangat),ataupun olahraga ringan Hindari juga kafein yang dapat meningkatkan pelepasan prostaglandin atau atasi dengan obat-obatan (Devi Eka Widiyanti,2013).

Berdasarkan survey awal yang peneliti lakukan di Universitas Dharmas Indonesia Koto Padang Dharmasraya pada tanggal 28 Februari 2018 melalui wawancara kepada 20 mahasiswi, didapatkan 14 mahasiswi yang mengalami nyeri haid pada saat menstruasi, dan tidak melakukan tindakan apa-apa untuk menuruni intensitas nyeri haid, sedangkan 6 orang mengalami nyeri haid dan 3 orang menangani dengan kompres hangat,3 orang menangani dengan tindakan lain.

Harapan peneliti adalah dengan adanya penelitian saya tentang Perbedaan intensitas nyeri haid sebelum dan sesudah diberikan kompres hangat pada remaja putri di ( Universitas Dharmas Indonesia) kabupaten Dharmasraya tahun 2018. Agar dapat membantu dan mengatasi masalah pada nyeri haid dan dapat menurunkan intensitas rasa nyeri tersebut dengan menggunakan tehnik kompres hangat, dan dapat membedakan intensitas nyeri sebelum dan sesudah kompres hangat dilakukan.

Dengan adanya landasan di atas, maka peneliti ingin mengetahui bagaimana perbedaan intensitas nyeri haid sebelum dan sesudah diberikan kompres hangat pada remaja putri di Universitas Dharmas Indonesia Dharmasraya, Tahun 2018.

\section{METODE}

Penelitian ini menggunakan metode eksperimen, yaitu suatu penenelitian dengan melakukan kegiatan percoban, yang bertujuan untuk mengetahui gejala atau pengaruh yang timbul,sebagai akibat dari adanya perakuan tertentu atau eksperimen tersebut. Penelitian ini menggunakan rancangan one grouppretest-post test only design yaitu penelitian dilakukan untuk mengetahui perubahan-perubahan yang terjadi setelah dilakukan perlakuan, dimana pengukuran dilakukan sebanyak $2 \mathrm{x}$, sebelum di berikan kompres hangat $\left(0_{1}\right)$ di sebut pre test dan sesudah diberikan kompres hangat $\left(0_{2}\right)$ di sebut post test.

Perbedaan antara $0_{1}$ dan $0_{2}$ dimaksudkan merupakan efek treatment dan exsperiment.

Pola

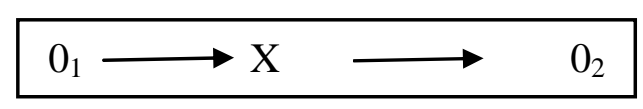

Penelitian adalah keseluruan objek penelitian atau objek yang diteliti (Notoatmodjo, 2012). Jumlah keseluruhan mahasiswi Fakultas Ilmu Kesehatan Prodi DIII Kebidanan Universitas Dharmas Indonesia sebanyak 63 orang. Pengambilan sampel menggunakan teknik non probability sampilng, tepatnya yaitu purposive sampilng. Waktu Penelitian telah dilaksanakan pada tanggal 19-23 agustus 2018. Dimana cara pengambilan sampelnya yaitu dengan pertimbangan yang di buat oleh peneliti sendiri, berdasarkan kriteria yang telah ditetapkan. Kriteria ini dapat di bedakan menjadi dua jenis yaitu inkulsi dan ekskulsi menurut Nursalam (2003) dikutip oleh A. Aziz Alimul Hidayat (2012), kriteria inklusi merupakan kriteria dimana subjek penelitian dapat mewakili sampel penelitian yang memenuhi syarat sebagai sampel. Pertimbangan ilmiah harus menjadi pedoman dalam menentukan kriteria inklusif (Notoatmodjo, 2010).

Kriteria inklusif dalam penelitian ini yaitu :

1. Remaja putri

2. Remaja putri yang sedang mengalami nyeri haid sebanyak 39 orang.

3. Bersedia menjadi responden dengan mengisi lembar persetujuan. 
Sedangkan kriteria eksklusi merupakan kriteria dimana subjek penelitian tidak dapat mewakili sampel karena tidak memenuhi sebagai syarat sebagai sampel penelitian yang penyebabnya antara lain yaitu :

1. Tidak bersedia menjadi responden

2. Tidak berada ditempat sewaktu penelitian setelah $3 \mathrm{x}$ berlangsung berturut-turut

3. Responden dalam keadaan tidak nyeri haid

Penetapan kriteria sampel (inklusi dan eksklusi) diperlukan dalam upaya untuk mengendalikan variabel penelitian yang tidak di teliti, tetapi memiliki pengaruh terhadap variabel independen. Dengan keterbatasan waktu, biaya, dan tenaga, maka tidak mungkin peneliti meneliti keseluruhan individu atau objek dalam populasi, untuk itu maka dilakukan pengambilan sampel (Notoatmodjo, 2010).

\section{HASIL DAN PEMBAHASAN}

\section{Hasil penelitian}

Tabel 4.1 Distribusi Frekuensi Perbedaan Intensitas Nyeri Haid Sebelum Diberikan Kompres Hangat Pada Remaja Putri Di Universitas Dharmas Indonesia

\begin{tabular}{cccc}
\hline NO & SESUDAH KOMPRES HANGAT & FREKUENSI & PERSEN $(\%)$ \\
\hline 1 & NYERI RINGAN & 3 & 7,7 \\
\hline 2 & NYERI SEDANG & 17 & 43,6 \\
\hline 3 & NYERI BERAT TERKONTROL & 17 & 43,6 \\
4 & NYERI BERAT TIDAK TERKONTROL & 2 & 5,1 \\
\hline \multicolumn{2}{c}{ TOTAL } & 39 & 100,0 \\
\hline
\end{tabular}

Berdasarkan tabel diatas didapatkan hampir setengahnya dari remaja putri DIII Kebidanan mengalami nyeri sedang yaitu 17 orang dan nyeri berat terkontrol yaitu 17 orang $(43,6 \%)$ sebelum diberikan kompres hangat.

Tabel 4.2 Distribusi Frekuensi Perbedaan Intensitas Nyeri Haid Sesudah Diberikan Kompres Hangat Pada Remaja Putri Di Universitas Dharmas Indonesia

\begin{tabular}{cccc}
\hline NO & SESUDAH KOMPRES HANGAT & FREKUENSI & PERSEN (\%) \\
\hline 1 & NYERI RINGAN & 8 & 20,5 \\
\hline 2 & NYERI SEDANG & 16 & 41,0 \\
\hline 3 & NYERI BERAT TERKONTROL & 15 & 38,5 \\
\hline & TOTAL & 39 & 100,0 \\
\hline
\end{tabular}

Berdasarkan tabel diatas didapatkan bahwa hampir setengahnya remaja putri DIII Kebidanan mengalami nyeri sedang yaitu 16 orang $(41,0 \%)$ setelah diberikan kompres hangat. 
Tabel 4.3 Perbedaan Intensitas Nyeri Haid Sebelum Dan Sesudah Di Berikan Kompres Hangat Pada Remaja Putri Di Universitas Dharmas Indonesia

\begin{tabular}{lccc}
\hline & N & Mediun(Minimum-maximum) & $p$-value \\
\hline Sebelum diberikan kompres hangat & 39 & $7,00(1-10)$ & 0,005 \\
\hline Sesudah diberikan kompres hangat & 39 & $5,00(1-8)$ & \\
\hline
\end{tabular}

Berdasarkan tabel 4.3 didapatkan Test statistic menunjukkan hasil ujiwilcoxon. Dengan uji wilcoxon diperoleh nilai signifikan 0,005 ( $p<0,05)$, dengan demikian disimpulkan ada perbedaan intensitas nyeri haid sebelum dan sesudah diberikan kompres hangat.

\section{Pembahasan}

Berdasarkan hasil penelitian menunjukkan bahwa hampir setengahnya dari remaja putri mengalami intensitas nyeri sedang dan nyeri berat terkontrol sebelum diberikan kompres hangat.

Dismenorea adalah nyeri saat haid,biasanya dengan rasa kram dan terpusat di abdomen bawah. Keluhan nyeri haid dapat terjadi bervariasi mulai dari yang ringan sampai yang berat. Keparahan disminorea berhubungan langsung dengan lama dan jumlah drah haid. Seperti diketahui haid hampir selallu diikuti dengan rasa mulas/nyeri (Prawirohardjo, 2011).

Intensitas nyeri adalah deskripsi tentang seberapa parah nyeri dirasakan olehindividu, pengukuran intensitas nyeri sangat subjektif dan individual dan kemungkinan nyeri dalam intensitas yang sama dirasakan sangat berbeda oleh dua orang yang berbeda, maka dari itu digunakan skala nyeri deskriptif dan numerik (Purnama, 2012).

Intensitas nyeri berat terkontrol adalah Terasa kram berat pada perut bagian bawah, nyeri menyebar kepinggang, paha atau punggung, tidak nafsu makan ,mual, lemas, hanya tertidur di tempat tidur,tidak dapat beraktivitas, tidak dapatberkosentrasi belajar.(Purnama,2012).

Dalam penatalaksanaan nyeri banyak hal yang dapat dilakukan untuk mengurangi nyeri dismenorea, baik melalui terapi farmakologis dan non-farmakologis. Terapi farmakologis dapat menggunakan obat untuk mengurangi nyeri tetapi dapat berdampak buruk bagi kesehatan tubuh diantaranya bisa mual, muntah, alergi, dan lain-lain. Terapi non-farmakologi berupa kompres hangat, pijatan pada pinggang,olahraga, nutrisi yang baik. Pijatan punggung memerlukan waktu yang lama serta membutuhkan bantuan orang lain, olahraga memerlukan gerakan fisik, nutrisi memerlukan biaya untuk menyediakan makanan yang dapat mengurangi dismenorea, dan terapi kompres hangat merupakan salah satu alternatif yang sangat efektif dalam menurunkan nyeri dismenorea, kompres hangat tidak memerlukan biaya yang banyak, waktu yang lama, serta dapat dilakukan sendiri. Dan terapi ini tidak menimbulkan dampak negatif bagi tubuh tetapi perlu diingat juga bahwa air yang terlalu panas dapat menimbulkan iritasi pada kulit (Dahlan, dkk 2017).

\section{Distribusi Frekuensi Sesudah Kompres Hangat}

Berdasarkan hasil penelitian menunjukkan bahwa hampir setengahnya remaja putri DIII Kebidanan mengalami nyeri sedang setelah diberikan kompres hangat.

Cara menurunkan dismenorea (nyeri haid) yaitu dengan pemakaian kompres hangat yang biasanya dilakukan hanya setempat saja pada bagian tubuh tertentu. Dengan pemberian panas, pembuluh-pembuluh darah akan melebar sehingga memperbaiki peredaran darah didalam jaringan tersebut. Dengan cara ini penyaluran zat asam dan bahan makanan ke sel-sel diperbesar dan pembuangan dari zat-zat yang di buang akan di perbaiki. Aktivitas sel yang meningkat akan mengurangi rasa sakit/nyeri sehinggga pasien akan merasa nyaman (Inut, dkk 2016).

Kompres hangat dapat mengakibatkan dilatasi atau membuka aliran darah yang mengakibatkan relaksasi dari otot. Suhu panas diketahui bias meminimalkan ketegangan otot. Akibatnya setelah otot rileks, rasa nyeri punberangsur - angsur hilang. Umumnya panas cukup bergauna untuk pengobatan. Dismenoea terjadi karena reaksi kontraksi otot miometrium yang mengakibatkan kontraksi berlebih yang membuat perut terasa mulas / nyeri, dan nyeri ini dapat diturunkan dengan kompres air hangat. Suhu yang hangat dapat membuatsir kulasi darah lancar, 
vaskularisasi lancer dan terjadinya vasodilatasi yang membuat relaksasi pada otot karena otot mendapat nutrisi berlebih yang dibawa oleh darah sehingga kontraksi otot menurun (Inut, dkk 2016).

\section{Perbedaan Intensitas Nyeri Haid Sebelum Dan Sesudah Diberikan Kompres Hangat Pada Remaja Putri}

Berdasarkan hasil penelitian Test statistic menggunakan uji wilcoxon. Maka diperoleh nilai signifikan 0,005 $(p<0,05)$, dengan demikian disimpulkan ada perbedaan intensitas nyeri haid sebelum dan sesudah diberikan kompres hangat.

Kompres hangat dapat digunakan pada pengobatan nyeri dan merelaksasikan otot-otot yang tegang, kompres hangat dilakukan dengan botol yang di isi air hangat secara konduksi dimana terjadi pemindahan panas dari botol ke perut sehinga perut yang dikompres menjadi hangat. Ini menyebabkan terjadi pelebaran pembuluh darah di bagian yang mengalami nyeri serta meningkatnya aliran darah pada daerah tersebut. Rasa hangat di bagian perut dapat meningkatnya relaksasi psikologis dan rasanyaman, sehingga dengan adanya rasa nyaman dapat menurunkan respon terhadap nyeri yang semula dirasakan.(Dahlan, dkk 2017).

Mekanisme terjadinya penurunan nyeri akibat dilakukan kompres hangat karena panas menyebabkan vasodilatasi pembuluh darah sehingga membantu meningkatkan aliran darah kebagian tubuh yang cidera atau mengalami perubahan fungsi, panas dapat meredakan nyeri dengan menyingkirkan produk-produk implamasi seperti bradikinin, histamine dan prostaglandin yang menimbulkan rasa nyerilokal. Panas juga dapat merangsang serat saraf yang menutup gerbang sehingga transmisi implus nyeri ke medulla spinalis dan otak dapat dihambat. Panas juga meningkatkan pengiriman nutrisi dan kebutuhan oksigen kedaerah itu dan kongesti vena menurun. Disamping itu panas mengurangi ketegangan otot menjadi relaksasi, menghilangkan ketegangan otot dan kekakuan sendi. Panas menurunkan nyeri melalui vasodilatasi dan efek relaksasi (Inut, dkk 2016). Menurut penelitian (Dahlan, 2017) menunjukan bahwa sebelum dilakukan perlakuan terapi kompres hangat banyak Siswi yang berada pada kategori sangat mengganggu (44\%) dan setelah dilakukan terapi kompres hangat terjadi penurunan yang banyak berada pada kategori sedikit sakit (56\%). Kompres hangat sangat efektif dilakukan untuk mengurangi nyeri dismenorea karena tidak memerlukan biaya yang banyak, waktu yang lama, dan kerja fisik yang berat tetapi harus tetap hatihati karena air yang terlalu panas dapat mengakibatkan iritasi pada kulit.

Dari hasil yang didapatkanbahwasanya kompres hangat sangat berpengaruh terhadap penurunan tingkat nyeri dismenorea. Menurut peneliti kompres hangat adalah suatu metode dalam penggunaan suhu hangat setempat yang dapat menimbulkan efek fisiologis (Dahlan,2017).

\section{KESIMPULAN DAN SARAN}

\section{Kesimpulan}

Berdasarkan hasil penelitian yang dilakukan dapat disimpulkan bahwa: Berdasarkan rumusan masalah dan pembahasan, maka dapat diambil kesimpulan : 1. Hampir setengahnya remaja putri DIII Kebidanan Universitas Dharmas Indonesia mengalami nyeri sedang dan nyeri berat terkontrol. 2. Hampir setengahnya remaja putri DIII Kebidanan Universitas Dharmas Indonesia mengalami nyeri sedang. .3 Ada perbedaan intensitas nyeri haid sebelum dan sesudah diberikan kompres hangat pada remaja putri DIII Kebidanan Universitas Dharmas Indonesia

\section{Saran}

Diharapkan penelitian ini dapat memberikan pemahaman kepada masyarakat khususnya remaja untuk dapat lebih memperluas penelitian ini guna mendapatkan hasil yang dapat memberikan pembaharuan dalam upaya penanganan intensitas nyeri haid dengan menggunakan kompres hangat. 


\section{DAFTAR PUSTAKA}

Pudiastuti. (2012). Tiga fase penting pada wanita. Jakarta. PT Gramedia.

Kumalasari. (2012). Kesehatan Reproduksi. Jakarta Selatan. Salemba Medika.

Prawihardjo. (2011). Ilmu Kandungan. Jakarta. Tridasa printer.

Notoatmodjo. (2012). Metodologi Penelitian Kesehatan. Jakarta. Rineka Cipta.

Notoatmodjo. (2010). Metodologi Penelitian Kesehatan. Jakarta. Rineka Cipta.

Dahlan. (2012). Statistik Untuk Kedokteran dan Kesehatan. Jakarta. Selemba Medika.

Dahlan. (2017). Pengaruh terapi kompres hangat terhadap nyeri haid atau disminorhea pada siswi SMK perbankan simpang haru padang. Stikes Ranah Minang Padang, Sumatera barat Indonesia.

Rofiqoh. (2017). Pengaruh Pemberian Kompres Air Hangat TerhadapPenurunan Intensitas Nyeri Dysmenorrhea PadaMahasiswi Stikes Jenderal Achmad YaniYogyakarta.Program Studi Ilmu Keperawatan (S1) Sekolah Tinggi Ilmu Kesehatan Jenderal Achmad Yani Yogyakarta.

Inut, dkk. (2016). Pengaruh Kompres Hangat Terhadap Penurunan Dismenorea Pada Mahasiswi D3 Kebidanan Angkatan 2014 Di Whn Malang. Mahasiswa Program Studi Ilmu Keperawatan Fakultas Ilmu Kesehatan Universitas Tribhuwana Tunggadewi Malang. Volume 1, Nomor 1, 2016.

Widiyanti. (2013). Pengaruh nyeri haid (Desminorea) Terhadap aktifitas sehari-hari pada remaja di smp $n 2$ ponorogo. Prodi DIII keperawatan fakultas ilmu kesehatan universitas muhammadiyah ponorogo.

Laili. (2012). Perbedaan Tingkat Nyeri Haid (Desminorea) Sebelum Dan Sesudah Senam Desminorea Pada Remaja Putri Di SMAN 2 Jember. Program Studi Ilmu Keperawatan Universitas Jember.

Hidayat, A. (2012). Metede Penelitian Kebidanan \& Teknik Analisa Data. Jakarta. Selemba. Medika.

Judha, dkk. (2012). Teori Pengukuran Nyeri Dan Nyeri Persalinan. Yogyakarta. Nuha Medika.

Kurniati. (2014). Perbedaan Efektivitas aroma therapy dan kompres hangatterhadapnyerihaiddi fakultas DIII kebidanan UMP. Program studi DIII kebidanan UMP. Jawa Tengah. 